\title{
Nociones técnicas de negociación y derecho colaborativo en conflictos de familia
}

\section{Technical notions of negotiation and collaborative law in family conflicts}

\author{
YASNA OTÁrola ${ }^{1}$ \\ Universidad de los Andes, Chile
}

\begin{abstract}
RESUMEN El artículo pretende responder a la pregunta sobre cuáles son los requerimientos prácticos que se necesitan cumplir para llevar adelante el cambio de paradigma que supone trabajar bajo los criterios del derecho colaborativo y dejar atrás el derecho controversial. Los conflictos de familia requieren considerar un sistema de resolución en que las partes, asistidas por abogados y otros profesionales, trabajen en la búsqueda consensuada de una solución integral del conflicto que satisfaga sus intereses y verdaderas necesidades. Esta necesidad motiva a estudiar este derecho desde el concepto hasta el diseño del proceso colaborativo, no sin antes ver las posibilidades de ejecutarlo. Todo lo anterior, con el objeto de darlo a conocer y propiciar su utilización por quienes se encuentran atravesando un conflicto familiar.
\end{abstract}

PALABRAS CLAVE Familia; negociación; técnicas; resolución de conflictos; proceso colaborativo.

ABSTRACT The present article aims to determine what practical requirements are necessary for the change in paradigm implied by working under the criteria of collaborative law instead of conflictive law. Family conflicts require a new resolution technique in which the parties, with the assistance of lawyers and other professionals, work together towards an integrated, mutually agreed solution to conflict that will satisfy their interests and their true needs. This requirement has motivated the author to study collaborative law from concept through to design of the collaborative process, in the belief that its application

1. Subdirectora de Doctorado de la Universidad de los Andes, Santiago de Chile. Abogada, Dra. en Derecho y Magíster en Ciencia Jurídica de la Pontificia Universidad Católica de Chile. E-mail: yotarola@uandes.cl. (iD) https://orcid.org/0000-0002-6245-3633 
is indeed possible. The final object is to disseminate this approach and encourage its use by people involved in family conflict.

KEYWORDS Family; negotiation; techniques; conflict resolution; collaborative process.

\section{Introducción}

Las familias deben hacer frente a diversas situaciones de dificultad que, si no se resuelven adecuadamente, producen mucho malestar y dolor entre sus integrantes, especialmente en los hijos. El conflicto se origina en situaciones propias de la convivencia y de las relaciones humanas, y por ello se dice que el conflicto es connatural a la vida misma, de modo que es casi imposible imaginar una familia en la que no existan desavenencias y que estas no se resuelvan. Sin embargo, muchas veces, las familias no saben cómo zanjar esos conflictos porque no cuentan con las habilidades para buscar y encontrar soluciones y terminan ventilándolos en los tribunales de justicia.

En ese sentido, se ha logrado evidenciar que la gestión de los conflictos en los tribunales de justicia eterniza las diferencias debido a la aspereza que genera que uno de los padres se sienta vencedor y el otro se sitúe dentro de los vencidos.

En dicho contexto, los "medios alternativos de solución de conflictos" (como la mediación, la negociación y la conciliación) se hacen cada vez más habituales y necesarios y generan un cambio positivo en el pensamiento de las personas y de los operadores jurídicos, porque ayudan a crear una cultura del no litigio y de la solución acordada de los conflictos. El conflicto aparece como la manifestación de un problema que necesita una solución conducente a buscar alternativas que lo resuelvan y atiendan las necesidades de todos los involucrados, con el fin de adoptar un acuerdo satisfactorio, duradero y estable para todos.

En Chile, desde 2006 se dio impulso a la gestión colaborativa de conflictos en ámbitos distintos al de familia, particularmente el penal y el comunitario, con distintos objetivos: facilitar el acceso a la justicia mediante acuerdos que consideren los intereses de los involucrados; disminuir la judicialización de los conflictos de relevancia jurídica; prevenir la violencia en la forma de abordarlos, por medio de mecanismos que se basan en el diálogo y el respeto entre los involucrados; promover la autogestión mediante la participación informada en los procesos de solución colaborativa de conflictos, y la responsabilización por las decisiones adoptadas ${ }^{2}$. Sin embargo, no se ha llegado a instalar el derecho colaborativo.

2. GOBIERNO DE CHILE (2015). 
El derecho colaborativo surge en los años 90 en Estados Unidos como respuesta a necesidades no satisfechas por el sistema de justicia, caracterizado por el ejercicio confrontacional de la abogacía. En efecto, en la ciudad de Minneapolis, Minnesota, el abogado Stuart WEBB fundó el divorcio colaborativo. Después de quince años de practicar la ley de divorcio, decidió hacer algo con respecto a todos los obstáculos y frustraciones con los que se encontraba constantemente resolviendo problemas de divorcio en la Corte ${ }^{3}$.

El derecho colaborativo consiste en que las partes asistidas por abogados y otros profesionales trabajan en la búsqueda consensuada de una solución integral del conflicto que satisfaga sus intereses y verdaderas necesidades, reservando la vía judicial para otorgar eficacia al acuerdo, o bien para cuando el procedimiento colaborativo no sea adecuado o no se haya conseguido un resultado positivo. La diferencia más notable dentro del proceso radica en que los abogados se abstienen de intervenir en un juicio posterior, en el evento de que las partes no logren acomodo. El éxito del derecho colaborativo y su potencial transformador están hoy fuera de toda duda; en Estados Unidos y Canadá, principalmente, y en otras muchas comunidades anglosajonas y europeas lo utilizan para resolver problemas familiares ${ }^{4}$. En tanto, en Latinoamérica, se ha establecido solo en algunos países, entre estos, Brasil y Argentina ${ }^{5}$.

Esto último motiva a estudiar el derecho colaborativo desde el concepto hasta el diseño del proceso colaborativo, no sin antes ver las posibilidades de ejecutarlo. Todo lo anterior, con el objeto de aprehenderlo desde la formulación teórica y práctica.

Así, el trabajo que se expone a continuación gira en torno a la pregunta sobre cuáles son los requerimientos prácticos que se necesitan cumplir para llevar adelante el cambio de paradigma que supone trabajar bajo los criterios del derecho colaborativo y dejar atrás el derecho controversial.

\section{El derecho colaborativo: concepto y elementos esenciales}

El derecho colaborativo ha sido definido como un proceso que permite a las partes que han decidido separarse o terminar su matrimonio trabajar con profesionales colaborativos de diversas disciplinas, incluidos abogados capacitados en colaboración. WEBB indica que este proceso evita el resultado incierto que ofrece que el asunto sea resuelto por un tribunal y permite lograr un acuerdo que satisfaga mejor las necesidades específicas de ambas partes y sus hijos, sin la amenaza presente de un juicio. El proceso se inicia cuando las partes suscriben un contrato de participación en el

3. WEBB (2008) p. 157.

4. TESLER (2003) p. 317.

5. Por ejemplo, en Argentina la Ley n. 26.589, reglamentada por el Decreto 1467/11, incorpora parcialmente una concepción colaborativa. 
proceso y excluyen la posibilidad de que los abogados que los representan intervengan en un futuro litigio relacionado con la familia ${ }^{6}$. ABNEY agrega que este enfoque es útil y satisfactorio en conflictos civiles cuando las partes están representadas por abogados que actúan honestamente y de buena fe en pos de alcanzar un acuerdo. Lamentablemente, estos requisitos no siempre se cumplen ${ }^{7}$. En particular, en el caso de conflictos de familia, los abogados se han dado cuenta de que los tribunales que conocen estas materias no son lugares efectivos para resolver disputas relacionadas con esta parte de la vida. El ejercicio del derecho colaborativo requiere de la convicción de trabajar en una forma de resolución de conflictos más positiva, defendiendo a los patrocinados bajo la circunscripción de los mandatos éticos del ejercicio de la profesión de abogado8.

Así, el derecho colaborativo se ha convertido en un método alternativo de solución de conflictos en el que participan abogados y otros profesionales preparados para dirimirlos y que requiere de la existencia de un convenio colaborativo.

La utilización de este procedimiento ha sido de gran utilidad debido a las fortalezas que se le atribuyen, en términos de que crea un ambiente de cooperación apoyado por especialistas que ayudan a llegar a acuerdo, lo que hace más fácil la relación posterior. La reunión de un equipo de abogados ofrece a las partes más alternativas de solución. Adicionalmente, es un proceso más rápido y de bajo costo comparado con un proceso judicial y que produce mejores acuerdos, sin tensionar o impactar $\tan$ fuertemente a los integrantes de la familia, padres y niños, si los hay ${ }^{9}$. Aunque también tiene desventajas, algunas de ellas son que puede tener un costo adicional si no se alcanza un acuerdo y que involucra el riesgo de que las partes actúen de mala fe, como sería si retardan el proceso intencionalmente y fuerzan las negociaciones de acuerdo con sus intereses ${ }^{10}$.

Con todo, otra debilidad que se debe considerar es que el ejercicio práctico de este derecho difiere de la controversia confrontacional que se lleva a cabo en los tribunales de justicia y, en consecuencia, resulta difícil que los abogados formados en este esquema asuman, sin más, trabajar naturalmente bajo esta modalidad, ya que para hacerlo necesitan formarse en derecho colaborativo ${ }^{11}$ y poseer ciertas virtudes personales.

6. WEBB (2008) p. 155.

7. ABNEY (1999) p. 277.

8. TESLER (2003) p. 318; JIMÉNEZ (2019) p. 4.

9. BALLESTEROS (2017) pp. 4-5.

10. CABRERA y AGUILERA (2019) pp. 266-267.

11. PARAMIO (2017) p. 467. 
La aplicación práctica de las habilidades de colaboración es fácil para algunos abogados, en tanto para otros es casi imposible, debido a que se centran en los intereses de su parte e ignoran los de la otra. De ahí que el abogado colaborativo -expone ÁLVAREZ- no negocia con el abogado de la contraparte sin la presencia de su parte y de la otra. Tampoco presiona para que se acepte el acuerdo; no detiene las peticiones porque pueden inhibir el acuerdo; no decide por las partes. Se dedica a asesorar y colaborar con su cliente para que sus verdaderas motivaciones y necesidades puedan terminar en un acuerdo ${ }^{12}$. En consecuencia, para poder ejercer este asesoramiento los abogados deben manejar conocimientos sobre las dinámicas familiares, manejar técnicas de negociación basadas en intereses y de estructura de pensamiento y, sobre todo, aprender a escuchar activamente ${ }^{13}$. "Es importante trabajar la escucha activa con el cliente, con el abogado de la contraparte y con la contraparte. [...] los abogados ya escuchamos (a veces más de lo que quisiéramos). Sin embargo, los abogados tenemos por formación jurídica, tendencia a ser resolutivos, de manera [...] que cuando un cliente comienza a explicar su situación, ya nos hemos construido el mapa legal y estamos organizando la prueba que permitirá afianzar sus posiciones en un juicio $[\ldots]^{\prime 14}$. Esto no es escuchar activamente. La escucha activa es una forma de comunicación que transmite ideas claras sin irrumpir al receptor; se realiza con libertad, teniendo en cuenta lo que piensan y sienten los demás, analizando, razonando y comprendiendo la información que se está transmitiendo en la conversación de una o varias personas ${ }^{15}$. Todo lo anterior es vital para generar seguridad y confianza, facilitar las relaciones con ambas partes y entenderlas en un proceso de colaboración.

Así, el derecho colaborativo se define sobre la base de la colaboración entre las partes y sus abogados; la exclusión de la vía judicial y el trabajo en red entre abogados y profesionales ${ }^{16}$.

\subsection{Principios que informan el procedimiento en el derecho colaborativo}

Desde su origen, el derecho colaborativo se ha desarrollado principalmente en el ámbito de la familia ${ }^{17} \mathrm{y}$, en concreto, en la solución de conflictos, luego del divorcio o la separación ${ }^{18}$. Estos conflictos se someten a un procedimiento informado por principios que orientan el actuar de los intervinientes, entre estos, se suele indicar

12. ÁLVAREZ (2020) p. 1

13. HOFFMAN y TESLER (2002) p. 11.

14. ÁLVAREZ (2020) p. 1.

15. HERNÁNDEZ y LESMES (2018) p. 84.

16. TESLER (2001) p. 8.

17. BALLESTEROS (2017) p. 15.

18. SOLETO (2012) p. 19. 
el trabajo en equipo, buena fe, confidencialidad, transparencia, solución compartida según los intereses de las partes y participación de varios profesionales ${ }^{19}$. O bien, el compromiso de colaboración, método autocompositivo, voluntariedad de las partes, confidencialidad e inhabilitación judicial de los profesionales ${ }^{20}$. Todos ellos coinciden en ciertos elementos fundamentales; por esta razón, se verán los que siguen.

En el primero, el trabajo en equipo, las personas que integran el grupo -partes, abogados y otros profesionales- cooperan para obtener un objetivo común. Esto supone interdependencia entre los miembros y sacar el máximo provecho de ellos en aras de conseguir el acuerdo. Cada miembro del equipo posee habilidades, conocimientos y experiencias específicos que aportar y que facilitan la defensa de las respectivas partes dentro de los límites de la responsabilidad profesional ${ }^{21}$.

La buena fe dice relación con la conducta correcta de todos los que intervienen en el proceso. Este comportamiento se hace evidente si las partes manifiestan disposición y actitud colaborativa en la búsqueda de las soluciones; respeto con todos los participantes y apertura y flexibilidad para evaluar otras alternativas de solución que pudieran surgir y que sean beneficiosas ${ }^{22}$.

La confidencialidad implica que la información que se trata en el procedimiento queda reservada solo para los participantes que intervienen en él, no pudiendo ser utilizada ni divulgada en un proceso posterior, ya sea judicial o de otra naturaleza. Este aspecto es muy importante y delicado, y así queda de manifiesto en un caso de Estate of Thottam (2008) 165 Cal.App.4th 1331, 81 Cal.Rptr. 856, sobre una disputa testamentaria/fiduciaria y patrimonial sobre la distribución de los bienes de la madre después de su muerte. Los hermanos herederos acordaron someterse a un procedimiento de resolución alternativa de conflictos y con ese objetivo firmaron un acuerdo que establece que todos los asuntos divulgados no se utilizarán en ningún juicio actual o futuro (excepto cuando sea necesario para cumplir cualquier acuerdo resultante del proceso). Durante este, las partes crearon un gráfico que bosquejó una división de activos y firmaron sus nombres en el dibujo, sin tener claro si eso era un acuerdo. Sin embargo, en un litigio posterior, una de las partes presenta el esquema como evidencia, pese a que era información de un proceso confidencial. La opinión del Tribunal de Apelación, basándose en el Código de Evidencia de California $\$ 1123$ (c), fue que el dibujo era admisible. Ese estatuto establece que un "acuerdo de conciliación por

\section{BUENO (2015) p. 112.}

20. The primary global collaborative organisation is the International Academy of Collaborative Professionals (IACP). En España, el derecho colaborativo surgió el año 2013 con la Asociación de Derecho Colaborativo de Euskadi, y posteriormente el año 2014 se creó la Asociación de Derecho Colaborativo de Madrid.

21. CARDONA y WILKINSON (2006) p. 2.

22. BRIZ (2015) p. 22. 
escrito [es admisible] si el acuerdo es firmado por las partes y [...] (c) todas las partes del acuerdo acuerdan expresamente por escrito [...] su divulgación”. En consecuencia, el tribunal determinó que el dibujo era un "acuerdo de conciliación por escrito", a los efectos del $\$$ 1123, y que las partes habían “acordado por escrito [...] su divulgación”, a los efectos del $\$ 1123(c)$, cuando firmaron el acuerdo previo a la mediación ${ }^{23}$.

La transparencia se refiere a la obligación de todos los intervinientes de revelar cualquier información de que dispongan en relación con los asuntos tratados en el proceso. Cualquier cambio material en la información debe ser actualizado de inmediato. Las partes autorizan a sus respectivos abogados a divulgar completamente toda la información que se debe proporcionar a los otros participantes para cumplir este compromiso, con esto se evita que quede información oculta que llegue a favorecer a alguna de las partes. El criterio para entregarla es si la divulgación perturba a la parte, solo en el caso de no hacerlo existe la obligación de proporcionarla. Obviamente, un abogado no puede revelar información en contra de los deseos del cliente, pero este debe ser consciente de las posibles consecuencias de su falta de voluntad para revelarla, incluida la posibilidad de que el proceso sea terminado por la otra parte y que se solicite la misma información, posteriormente, en un juicio. Los acuerdos contienen cláusulas que establecen la revelación completa de información entre los participantes en el proceso. Este es un requisito que diversos tribunales han adoptado como regla de procedimiento y conducta profesional con respecto al proceso de colaboración. Esto porque en ocasiones las partes han debido solicitar que se deje sin efecto el acuerdo por esta causa. Por ejemplo, en Ward v. Ward, 2010 ONSC 1007 (Juez Matheson, Tribunal Superior de Justicia de Ontario), una de las partes solicitó que se anulara el acuerdo porque la otra parte no cumplió con su deber de revelar información sobre activos significativos. La falta de revelación de activos significativos incluye tergiversar materialmente el verdadero valor de los activos, y la falta de revelación de cambios en los ingresos. Si el tribunal determina que una parte no ha informado un activo significativo, deberá decidir, a la luz de los hechos, si debe rescindir el contrato ${ }^{24}$.

Otro principio es la solución compartida, esto es, el acuerdo al que se llegue en un proceso colaborativo debe reunir los intereses y necesidades de las partes intervinientes $y$, en ese sentido, el objetivo es conseguir el mejor acuerdo posible.

La voluntariedad implica que la participación de todas las partes es libre, no siendo posible obligarlas a permanecer en el procedimiento, ni mucho menos a concluir un acuerdo si no se satisfacen sus legítimos intereses y expectativas. El abogado colaborativo debe explicarle al cliente que el proceso puede ser rescindido por el cliente

23. BADER (2009).

24. Ward vs Ward (2010); Sekhon vs Khangura (2009); Frolick vs Frolick (2007). 
en cualquier momento y por cualquier motivo. Así ocurrió en el proceso Banerjee v. Bisset, 2009 BCSC 1808 , en que las partes y sus respectivos abogados especializados en derecho colaborativo firmaron un acuerdo titulado "Acuerdo de participación en derecho colaborativo". Las partes y sus abogados tuvieron una larga reunión a cuatro bandas. El 7 de agosto de 2009, y luego nuevamente el 21 de agosto de 2009, la acusada notificó, a través de su abogado, que se retiraba del proceso de colaboración de la ley. Posteriormente, la otra parte solicitó al tribunal que declarara que habían firmado un acuerdo válido y vinculante que se ocupaba de todos los asuntos de propiedad y sostenimiento conyugal. El tribunal resolvió que cada contendiente se hacía parte de los costos de mantenimiento ${ }^{25}$.

En otro caso, denominado Hogan v. Hogan, 2011 SKQB 479 (CanLII), las partes intentaron resolver la distribución de los bienes a través del proceso de derecho colaborativo. Una de las partes decidió que era poco probable que lograran una solución mediante este proceso y buscó un abogado alternativo para proceder a un litigio. En el juicio exhibió una serie de documentos que obtuvo a propósito del procedimiento. El demandado presentó una moción argumentando que los documentos intercambiados en el proceso de derecho colaborativo no pueden usarse en el tribunal. Este reflexionó sobre los principios en discusión, a saber, que todas las pruebas relevantes deberían estar disponibles para el tribunal y que las comunicaciones entre el abogado y el cliente deberían ser confidenciales y privilegiadas. Al conciliar esos dos principios, el interés público permitió determinar los límites del privilegio que autoriza a retener legalmente evidencia relevante para un litigio. En consecuencia, los documentos están sujetos al privilegio si el propósito dominante para el que se prepararon era presentarlos a un asesor legal para que lo aconsejara. Dado que el propósito de preparar el informe de consulta interna para asesoramiento era simplemente uno de los propósitos y no el propósito dominante, de modo que puede ser divulgado ${ }^{26}$.

El control del procedimiento está determinado por las partes que intervienen y el procedimiento diseñado; no obstante, a diferencia de un juicio, es gestionado de una manera más expedita e inmediata y conforme a las necesidades de las partes ${ }^{27}$.

Finalmente, la flexibilidad se refiere a que los métodos alternativos de solución de conflictos se adaptan a las necesidades de las partes; sin embargo, esto no significa que no contemplen formalidades, sino que su desarrollo se ajusta a ciertos principios, así como a una serie de normas para un mejor funcionamiento ${ }^{28}$.

\section{Banerjee vs Bisset (2009).}

26. Hogan vs Hogan (2011).

27. PARAMIO (2017) p. 467

28. El párrafo 2013 del Código Familiar de California (California Family Code) señala que (a) si las partes firman un acuerdo por escrito, estas pueden utilizar un proceso de derecho colaborativo para resolver cualquier asunto regido por este código sobre el cual se otorga jurisdicción al tribunal, de conformidad con la Sección 2000. 
Todos estos principios son fundamentales para el desarrollo del procedimiento y para asegurarlos se consignan en un "Acuerdo de participación" que se firma al comienzo del proceso por las partes y sus abogados y, por lo tanto, deben ser cumplidos y respetados.

En Chile una de las manifestaciones más relevantes en materia de "solución colaborativa" se da en las causas de familia, la Ley $\mathrm{N}^{\circ} 19.968$ en su artículo 75 reza: "Sentencia. Antes de pronunciar sentencia, el juez procurará que las partes acuerden la forma más conducente a la resolución de la situación que afecta al niño, niña o adolescente. Si ello no fuere posible, en la sentencia fundamentará la necesidad y conveniencia de la medida adoptada, indicará los objetivos que se pretenden cumplir con ella y determinará el tiempo de su duración". De la lectura anterior, junto con la praxis judicial, la solución colaborativa se plantea como una instancia previa en el marco de una audiencia preparatoria o de juicio, en el que las partes, abogados y consejero técnico, proponen bases de un acuerdo, a fin de evitar una sobre judicialización del proceso. Por ejemplo, en materia de medida de protección en favor de NNA, la solución colaborativa tiene lugar en el momento previo a una audiencia preparatoria o de juicio; las partes, los abogados, el curador ad-litem y el consejero técnico buscan una solución que logre satisfacer la necesidad de las partes, y que se respalde en los principios que informan el derecho de familia chileno. Así las cosas, la Corporación de Asistencia Judicial de Chile, reconoce y motiva la solución colaborativa como término de conflictos, y encuentra su sustento en los mismos principios que se expusieron previamente ${ }^{29}$.

(b) "Proceso de derecho colaborativo" significa el proceso en el cual las partes y los profesionales contratados por ellas acuerdan por escrito utilizar sus mejores esfuerzos y hacer un intento de buena fe para resolver disputas relacionadas con asuntos de derecho de familia [...] (a) sobre una base acordada sin recurrir a la intervención judicial adversarial.

También, los Estatutos de Florida 2019 establecen en la Sección 61.56 que (1) "Abogado colaborativo" significa un abogado que representa a una parte en un proceso de derecho colaborativo.

(2) "Comunicación de derecho colaborativo" significa una declaración oral o escrita, incluida una declaración hecha en un registro, o una conducta no verbal que:(a) se lleva a cabo en el curso del procedimiento, [...]; y (b) Ocurre después de que las partes firman un acuerdo de participación en la ley de colaboración y antes de que se concluya o finalice el proceso de la ley de colaboración.

(3) "Acuerdo de participación en derecho colaborativo" significa un acuerdo entre personas para participar en un proceso de derecho colaborativo.

(4) "Proceso de derecho colaborativo" significa un proceso destinado a resolver un asunto de colaboración sin intervención de un tribunal y en el que las personas firman un acuerdo de participación de derecho de colaboración y están representadas por abogados de colaboración. Disponible en: https://codes.findlaw.com/ca/family-code/fam-sect-2013.html.

29. "El objetivo, es ofrecer, a personas de escasos recursos, la oportunidad de obtener, antes de litigar ante Tribunales, una solución a conflictos familiares, de vivienda, laborales, vecinales, entre otros, que les represente en sus intereses y que surja desde ellos como los principales protagonistas de su acuerdo. 


\subsection{El acuerdo de participación}

Uno de los elementos centrales que distingue una representación de derecho colaborativo es que el proceso comienza cuando las partes y abogados firman un acuerdo vinculante (denominado "acuerdo de participación" o "estipulación de colaboración") que prohíbe a los abogados participar en procedimientos judiciales en su representación, de modo que quedan limitados a trabajar hacia un acuerdo. Cumplido este elemento central, el caso es de derecho colaborativo.

El acuerdo de participación es una de las características del proceso de derecho colaborativo. Este acuerdo detalla los derechos y responsabilidades de las partes y sus abogados en el proceso de colaboración.

Los acuerdos de participación generalmente se inician con una introducción que indica que las partes han optado por comprometerse y utilizar los principios del proceso colaborativo para resolver de forma pacífica y privada los problemas familiares que someten al proceso. A continuación, nombran al abogado que representará a cada parte y que les ayudará a cumplir el objetivo ${ }^{30}$.

Las partes, en el acuerdo, asumen una serie de obligaciones generales y específicas. Las primeras imponen abstenerse de usar técnicas de litigio y, al contrario, adoptar esta forma de resolución alternativa de conflictos, que no es impuesta como la de un tribunal. Las segundas comprenden resolver los problemas de familia sin la intervención judicial durante el proceso de colaboración, esto es, antes de llegar a un acuerdo final. Si cualquiera de las partes inicia un procedimiento de esta naturaleza, el proceso de colaboración termina de inmediato.

Ahora bien, respecto de la participación del abogado colaborativo, se circunscribe al proceso y a la representación no contenciosa. Si bien cada abogado es el asesor de su representado y sirve de consejero y defensor, las partes acuerdan que ninguno de los abogados puede representarlas en un proceso judicial contencioso contra la otra parte.

\footnotetext{
Los profesionales son los que, por medio del diálogo, en un marco de respeto y escucha activa de las posiciones e intereses de cada una de las partes, proponen las bases que sustentarán y propiciarán la búsqueda de acuerdos. En el caso que existan niños o niñas, se velará siempre por su interés superior en todo lo relativo a la protección de sus derechos fundamentales. Esto siempre dentro del marco legislativo vigente que rige los temas planteados por las personas.

Este proceso, en todo sentido, tiene el carácter de voluntario, por lo que nada se puede imponer a las personas respecto de la forma y condiciones para poner término al conflicto. Por otra parte, el profesional mantendrá estricta reserva respecto a lo conversado por las partes, actuando en todo momento de manera imparcial" (Corporación de Asistencia Judicial Región Metropolitana, disponible en: http://www.cajmetro.cl/resolucion-alternativa-de-conflictos/).
}

30. COX y MATLOCK (2004) pp. 55-56. 
Sobre el deber de información, el acuerdo de participación impone que las partes proporcionarán toda la información importante, ya sea solicitada o no, para el proceso. Se considera información relevante cualquiera que las partes necesiten para tomar una decisión informada sobre cada problema que deba resolverse. Complementariamente, existe un compromiso de no emplear procedimientos de investigación, debido a que el acuerdo está basado en la confianza depositada por cada parte en la otra. De modo que si alguna tergiversa o retiene información importante, el proceso finaliza ${ }^{31}$.

El acuerdo también contempla el desarrollo del procedimiento, y uno de los puntos en ese orden es la interacción entre las partes y cómo se llevará a cabo la comunicación. En ese sentido, las partes acuerdan realizar una serie de reuniones que incluirán a los abogados y a otros profesionales. En estas reuniones se intentará adoptar posiciones flexibles, entendiendo que el ajuste de los intereses de los demás y la capacidad de compromiso son esenciales para el éxito de este proceso. De ahí que el foco está en los problemas que se deben resolver.

En tanto, fuera del proceso, se establece que las partes pueden comunicarse y a través de esta comunicación expresar sus intereses, necesidades y opciones sin preocuparse de las críticas ni tampoco de las presiones para llegar a acuerdo. Las comunicaciones con el abogado que tienen por objeto la asesoría legal pueden darse en la reunión o en privado, pero en este último caso, el grueso de esa comunicación debe compartirse con el grupo en la próxima reunión, debido a que existe el compromiso de entregar toda la información, no obstante el secreto profesional.

En el evento de que haya hijos, las partes se comprometen a minimizar el trauma y no afectar la vida de estos. Para ello, convienen que los acuerdos no serán discutidos en presencia de niños, niñas y adolescentes (NNA). La comunicación con los NNA, con respecto a los problemas, ocurrirá solo si es apropiado y se realiza de mutuo acuerdo y/o con el consejo de un profesional. Los NNA no serán interrogados ni colocados en medio de los desacuerdos de las partes.

Enseguida, si las partes llegan a acuerdos "temporales", estos constituyen instrumentos que deben ser respetados y seguidos por las partes durante el transcurso del proceso. No hacerlo no solo impide llegar a acuerdo, sino que es causal de término del proceso. Las partes entienden que un acuerdo escrito firmado por ellas durante el proceso es un acuerdo legalmente ejecutable en el que se puede confiar y que puede presentarse ante el tribunal. Cuando las partes hayan llegado a un acuerdo sobre todas las cuestiones, sus acuerdos temporales se reducirán a un documento escrito que será un contrato exigible, que obligará a las partes a cumplir sus términos. Este contrato puede presentarse a un tribunal en una acción posterior.

31. SOLOVAY y MAXWELL (2009) p. 38. 
Una vez llegado a acuerdo, el proceso finaliza y ningún miembro del equipo puede participar en ningún juicio posterior entre las partes, incluso si estas estiman lo contrario y desean la participación de los miembros del equipo.

Sin embargo, el proceso puede terminar también porque una parte decide retirarse de este; en dicho caso, debe dar un aviso por escrito de inmediato. También, por el abogado de una de las partes si el patrocinado ha actuado de forma contraria al consejo dado, ha retenido o tergiversado información; en fin, si sus acciones han socavado el proceso de colaboración.

Si alguno de los abogados considera apropiado retirarse del caso por cualquier motivo, debe informar a su patrocinado, al otro abogado y a todos los demás profesionales involucrados. Lo mismo ocurre si se retira otro miembro del equipo. En todas estas situaciones, las partes deben hacer lo posible para reemplazarlos ${ }^{32}$.

Finalmente, cada parte se encarga de instruir a su abogado para que lo ayude a cumplir el acuerdo y a actuar de manera compatible con este.

\subsection{Desarrollo del procedimiento en el derecho colaborativo}

En general, el proceso de derecho colaborativo se inicia con una reunión con la parte potencial en la que se explica en qué consiste el derecho colaborativo y las normas que lo regulan.

Estas disposiciones han sido incorporadas en algunos estados y países debido a que se presentaron situaciones en las que no se sabía qué hacer ${ }^{33}$. Por ejemplo, sobre si una pareja elige usar el proceso de colaboración mientras una acción de divorcio o paternidad está pendiente en la Corte; qué hacer después de que se resuelva el asunto familiar y qué hacer si el asunto familiar no se resuelve utilizando el proceso de colaboración. En este sentido, en los Estados Unidos, la Ley de 2009 que uniforma el derecho colaborativo y que luego fue modificada el año 2010 estandariza las características más importantes de la práctica del derecho colaborativo, teniendo presente las consideraciones éticas y el privilegio de confidencialidad ${ }^{34}$.

Posteriormente, se verifica si la persona reúne las condiciones personales para participar en un procedimiento alternativo de resolución de conflictos, debido a que la intervención es una decisión que requiere voluntad de la parte que acepta, de modo

\section{FAIRMAN (2005) p. 91.}

33. En el año 2013, se promulgó en los estados de Utah, Nevada, Texas, Hawái, Ohio, el Distrito de Columbia y de Washington. En el año 2016, la Ley de derecho colaborativo de Florida crea un privilegio legal que considera confidenciales las comunicaciones que se hayan tenido durante el proceso de colaboración. The 2019 Florida Statutes - Statutes \& Constitution. Official internet site of the Florida legislature.

34. ULC. Uniform Law Commission. The national conference of commissioners on uniform state laws. 
que debe ser capaz de tomar decisiones y estar llana a colaborar. No todas las personas tienen esa aptitud, de manera que puede no ser siempre la mejor opción para sus necesidades; en concreto, se trata de situaciones tales como: "a) una o ambas partes padecen algún tipo de enfermedad mental no tratada; una o ambas partes son drogodependientes o sufren adicción a determinadas sustancias, de forma que su capacidad de percepción y toma de decisiones se encuentre alterada; existen delitos o episodios de violencia entre las partes; una de las partes carece de la capacidad de participar plena y libremente en el proceso por sufrir miedo o intimidación y e) una o ambas partes están predispuestas a mentir en orden de conseguir el acuerdo predeterminado que desean" 35 . Comprobado aquello, se indaga si a la otra parte le interesa iniciar un proceso y suscribir un acuerdo. Para participar, cada parte necesita representación de un abogado colaborativo y estar ambos de acuerdo en asumir el compromiso y, por consiguiente, los derechos y deberes que esto implica. Esto último lleva a una característica esencial de la práctica colaborativa, esto es, el cumplimiento de los códigos éticos establecidos en las regulaciones de los países y estados que han normado este método de resolución alternativa de conflictos. En los hechos, esto significa que los abogados de las partes solo pueden representarlas en este procedimiento, no están autorizados para hacerlo en los juicios ante los tribunales de justicia. De ahí que resulta fundamental el consentimiento informado por escrito del interesado en torno a que el abogado no puede trascender a una disputa de naturaleza confrontacional ${ }^{36}$.

Una vez que las partes tienen abogado, estos se contactan entre sí para identificar los potenciales puntos críticos del proceso; comienzan a acumular la información y los documentos de las partes, con el objeto de diseñar una agenda para la primera reunión de cuatro, es decir, dos partes y los abogados de cada una de ellas ${ }^{37}$. En esa reunión se firma el acuerdo de participación. El documento es revisado cuidadosamente por todos los intervinientes, pues establece las reglas y protocolos que regirán la forma en que debe proceder el proceso de colaboración.

Al finalizar la primera reunión, los abogados colaborativos se reúnen con su parte $\mathrm{y}$, posteriormente, con el otro abogado para revisar las distintas percepciones. Concluida esta fase, si todos los pasos previos se han realizado correctamente, se puede seguir adelante con el proceso.

A continuación, transcurre una serie de reuniones en las que se identifican y tratan cada una de sus diferencias; se comparte información; se desarrollan opciones de posibles acuerdos y se evalúan las posibilidades. Todo el caso se negocia ahí, no obstante el contacto privado entre patrocinado y abogado, ya sea para dar consejo

35. ESTEVE (2016) p. 84.

36. PARAMIO (2017) pp. 475-476.

37. ESTEVE (2016) p. 86. 
o realizar las tareas asignadas en la reunión. A las reuniones se irán sumando otros profesionales para ayudar con el caso; por ejemplo, elaboran informes y se comunican con los intervinientes. Debido a que el derecho colaborativo es un proceso centrado en las partes, ellas eligen qué profesionales incluir y cómo utilizarlos.

Una vez que se llega a un acuerdo completo, uno o ambos abogados prepararán toda la documentación necesaria, la cual se utiliza para elaborar el convenio que lo contiene y termina el proceso. Empero, ha de recordarse que puede finalizar por otras circunstancias: si cualquiera de las partes unilateralmente decide terminar el proceso sin llegar a acuerdos; el abogado colaborativo se retira o una de las partes inicia un procedimiento contra la otra en relación con el objeto del proceso colaborativo.

En suma, el procedimiento se compone de una fase preliminar que incluye los primeros contactos con las partes; una segunda en la que se preparan las negociaciones; la tercera, que es la negociación propiamente tal, y el acuerdo que implica el término del proceso. Todo este iter, con la finalidad de que las partes mediante un proceso que ellas manejan puedan llegar a un acuerdo que resuelva los conflictos, poniendo sus intereses en común y a través del diálogo entre ellas.

\section{Conclusiones}

El derecho colaborativo constituye un método para resolver los conflictos de familia y otros; se presenta como alternativa frente a los procesos confrontacionales que se llevan a cabo en el tribunal y que a veces no solucionan las desavenencias, sino que las prolongan. Esta opción permite que los integrantes de la familia participen en la solución de sus propios conflictos y, lo más importante, son quienes toman la decisión final. Sin duda, esto representa un gran avance para mantener a la familia unida y otorgar o mantener el bienestar de los hijos, si los hay.

En Chile, desde el Estado no existe una alternativa igual, sí se incorporó la mediación en la regulación, y en la práctica unas veces tiene éxito y otras no, al igual que ocurre con el proceso que se realiza en el derecho colaborativo. Sin embargo, considerando las ventajas descritas y la participación de las partes en la construcción del acuerdo, bien podríamos avanzar como país en su utilización. De modo que sería conveniente adoptar esta figura que tan amplia aceptación tiene, en principio, por decisión personal y de forma particular mediante la contratación de profesionales que se dediquen a esta área del derecho.

Una vez analizada la figura, concepto, elementos, requisitos, principios y procedimientos, este proceso se presenta como una opción para resolver disputas, con el asesoramiento de abogados y la participación de profesionales de otras disciplinas que ponen a disposición de las partes sus conocimientos para dar seguridad a la hora de alcanzar un acuerdo. 
Este artículo contribuye a dar a conocer el derecho colaborativo, en especial a quienes se encuentran atravesando por un conflicto de familia. Sin duda que esto último requiere de abogados virtuosos y capacitados que se dediquen al tema en particular.

En definitiva, la justicia alternativa que ofrece el derecho colaborativo es una nueva forma de solucionar conflictos, pero no de la manera tradicional, sino que se presenta como la posibilidad real de que partes involucradas en una controversia logren juntas un acuerdo que ponga punto final a su problema.

\section{Referencias bibliográficas}

ABNEY, Sherrie (1999): Civil Collaborative Law: The Road Less Travelled (Indiana, USA, Trafford Publishing).

ÁLVAREZ, Soledad (2020): “Cambio de paradigma en el derecho de familia. La oportunidad del derecho colaborativo: otra forma de negociar". Disponible en: https:// www.lawyerpress.com/2020/o5/29/cambio-de-paradigma-en-el-derecho-de-familia-la-oportunidad-del-derecho-colaborativo-otra-forma-de-negociar/. [Fecha consulta: 22 de agosto de 2020].

BADER, Elizabeth (20o): “Confidentiality in Collaborative Cases After Thottam”. Disponible en: https://www.mediate.com/articles/badere1.cfm. [Fecha de consulta: 11 de agosto de 2020].

BALLESTEROS, Ana (2017): "El Derecho Colaborativo: una forma más humana para la solución de controversias", Tesis para obtener la Maestría en Abogacía, Universidad de Oviedo, España.

BRIZ, María José (2015): “El principio de buena fe en el proceso de mediación”. En Revista de Derecho, segunda época, n. ${ }^{\circ}$ 11, pp. 13-25.

BUENO, Luis (2015): “Cruce y descruce de miradas al Derecho Colaborativo". En Icade. Revista de la Facultad de Derecho, (95), pp. 105-121.

CABRERA, Julio y AGUILERA, Jesús (2019): "La justicia alternativa, el derecho colaborativo y sus perspectivas en México". En Revista Mexicana de Derecho Constitucional, n. ${ }^{\circ}$ o, pp. 243-275.

CARDONA, Pablo y WILKINSON, Helen (2006): “Trabajo en equipo”. En Occasional Paper OP, n. ${ }^{\circ}$ o7/10.

COX, Gay y MATLOCK, Robert (2004): “The Case for Collaborative Law”. En Texas Wesleyan Law, Review 11, n. ${ }^{\circ}$, pp. 45-70.

ESTEVE, Patricia (2016): “Una nueva forma de resolución de conflictos”. En Revista Jurídica de Catalunya, n. ${ }^{\circ}$, pp. 71-95. 
FAIRMAN, Christopher M. (2005): "A Proposed Model Rule for Collaborative Law". En Ohio State Journal on Dispute Resolution, n. ${ }^{\circ}$, pp. 73-122.

GOBIERNO DE CHILE y CORPORACIÓN DE ASISTENCIA JUDICIAL (2015): "Modelo de atención. Línea de solución colaborativa de conflictos". Disponible en: http://www.cajmetro.cl/wp-content/files_mf/modelosccjunio2015versi\%C3\%B3n definitiva29.pdf. [Fecha de consulta: 05 de agosto de 2020].

HERNÁNDEZ, Karen y LESMES, Anggy (2018): "La escucha activa como elemento necesario para el diálogo”. En Convicciones, 9(1), pp. 83-87.

HOFFMAN, David y TESLER, Pauline (2002): "Collaborative Law and the Use of Settlement Counsel”, en: ROTH, B.; WULFF, R.; COOPER, Ch. (eds.). Alternative Dispute Resolution Practice Guide (Estados Unidos, West Publishing).

JIMÉNEZ, Irene et al. (2019): "El derecho colaborativo. Innovación social basada en la resolución alternativa de conflictos". En XI Congreso Internacional de casos docentes en marketing público y no lucrativo. Disponible en: https://addi.ehu.es/ handle/10810/42617

PARAMIO, Nieves (2017): “Derecho colaborativo: de la teoría a la práctica”. En Academia Vasca de Derecho. Boletín JADO, año XV, n. ${ }^{\circ}$ 28, pp. 455-504.

SOLETO, Helena (2012): "La nueva normativa de mediación y la oportunidad de impulsar una práctica colaborativa del Derecho". En Revista El Notario del Siglo XXI, n. ${ }^{\circ} 43$, pp. 18-21.

SOLOVAY, Norman y MAXWELL, Lawrence R. (2009): "Why a Uniform Collaborative Law Act?”. En New York Dispute Resolution Lawyer, vol. 2, n. ․ 1. p. 36.

TESLER, Pauline H. (2001): Collaborative Law: Achieving Effective Resolution in Divorce Without Litigation, 2nd revised edition (USA, American Bar Association).

TESLER, Pauline H. (2003): "Collaborative Family Law”. En Pepp. Disp. Resol. LJ, vol. 4, Iss. 3, pp. 317-336.

WEBB, Stuart (2008): “Collaborative Law: A practitioner's perspective on its history and current Practice”. En J. Am. Acad. Matrimonial Law, vol. 21, pp. 155-169.

\section{Jurisprudencia citada}

Ward v. Ward (2010): Corte Superior de Justicia de Ontario (Canadá), 26 de febrero de 2010. Decision on motion for summary judgment" ONSC 1007 Disponible en: http://canlii.ca/t/28ccl.

Sekhon v. Khangura (2009): Corte Suprema de Columbia Británica (Canadá), 20 de mayo de 2009 BCSC 670. Disponible en: http://canlii.ca/t/23l6b. 
Frolick v. Frolick (2007): Corte Suprema de Columbia Británica (Canadá), 18 de enero de 2007 BCSC 84. Disponible en: http://canlii.ca/t/1q91k.

Banerjee v. Bisset (2009): Corte Suprema de Columbia Británica (Canadá), 6 de noviembre de 2009 BCSC 1808. Disponible en: http://canlii.ca/t/27932.

Hogan v. Hogan (2011): Bancada de Queen, Saskatchewan (Canadá), 19 de diciembre de 2011 SKQB 479. Disponible en: http://canlii.ca/t/fplqh. 